University of Nebraska - Lincoln

DigitalCommons@University of Nebraska - Lincoln

Public Health Resources

Public Health Resources

2007

\title{
Relaxin Receptors in Hepatic Stellate Cells and Cirrhotic Liver
}

Robert G. Bennett

Department of Medical Research, Veterans Affairs Medical Center, Omaha, NE, USA

Shana R. Dalton

Department of Medical Research, Veterans Affairs Medical Center, Omaha, NE, USA

Katrina J. Mahan

Department of Medical Research, Veterans Affairs Medical Center, Omaha, NE, USA

Martha J. Gentry-Nielsen

Department of Medical Research, Veterans Affairs Medical Center, Omaha, NE, USA

Frederick G. Hamel

Department of Medical Research, Veterans Affairs Medical Center, Omaha, NE, USA

See next page for additional authors

Follow this and additional works at: https://digitalcommons.unl.edu/publichealthresources

Part of the Public Health Commons

Bennett, Robert G.; Dalton, Shana R.; Mahan, Katrina J.; Gentry-Nielsen, Martha J.; Hamel, Frederick G.; and Tuma, Dean J., "Relaxin Receptors in Hepatic Stellate Cells and Cirrhotic Liver" (2007). Public Health Resources. 14.

https://digitalcommons.unl.edu/publichealthresources/14

This Article is brought to you for free and open access by the Public Health Resources at DigitalCommons@University of Nebraska - Lincoln. It has been accepted for inclusion in Public Health Resources by an authorized administrator of DigitalCommons@University of Nebraska - Lincoln. 
Authors

Robert G. Bennett, Shana R. Dalton, Katrina J. Mahan, Martha J. Gentry-Nielsen, Frederick G. Hamel, and Dean J. Tuma 


\title{
Relaxin receptors in hepatic stellate cells and cirrhotic liver
}

\author{
Robert G. Bennett ${ }^{a, b, c, *}$, Shana R. Dalton ${ }^{a, b}$, Katrina J. Mahan ${ }^{a}$, \\ Martha J. Gentry-Nielsen ${ }^{a, d}$, Frederick G. Hamel ${ }^{a, b, c}$, Dean J. Tuma ${ }^{a, b}$ \\ ${ }^{a}$ Department of Medical Research, Veterans Affairs Medical Center, Omaha, NE, USA \\ ${ }^{\mathrm{b}}$ Department of Internal Medicine, University of Nebraska Medical Center, Omaha, NE, USA \\ ${ }^{c}$ Department of Pharmacology, University of Nebraska Medical Center, Omaha, NE, USA \\ ${ }^{\mathrm{d} C r e i g h t o n}$ University School of Medicine, Omaha, NE, USA
}

\section{A R T I C L E I N F O}

\section{Article history:}

Received 26 September 2006

Accepted 7 December 2006

\section{Keywords:}

Fibrosis

LGR7

LGR8

InsL3

Relaxin-3

\begin{abstract}
A B S T R A C T
The polypeptide hormone relaxin has antifibrotic effects on a number of tissues, including the liver. Central to the progression of hepatic fibrosis is the transdifferentiation of hepatic stellate cells (HSC) from a quiescent state to an activated, myofibroblastic phenotype that secretes fibrillar collagen. Relaxin inhibits markers of HSC activation, but relaxin receptor expression in the liver is unclear. The purpose of this study was to determine the expression of the relaxin receptors LGR7 and LGR8 in activated HSC. Production of cAMP was induced by treatment of HSC with relaxin, or the relaxin-related peptides InsL3 or relaxin-3, selective activators of LGR8 and LGR7, respectively. Quiescent HSC expressed low levels of LGR7 but not LGR8. During progression to the activated phenotype, expression of both receptors increased markedly. Immunocytochemistry confirmed the presence of both receptors in activated HSC. In normal rat liver, LGR7, but not LGR8, was expressed at low levels. In cirrhotic liver, expression of both receptors significantly increased. Neither receptor was detectable in normal liver by immunohistochemistry, but both LGR7 and LGR8 were readily detectable in cirrhosis. These results were confirmed in human cirrhotic tissue, with the additional finding of occasional perisinusoidal LGR7 immunoreactivity in non-cirrhotic tissue. In conclusion, the expression of LGR7 and LGR8 is increased with activation of HSC in culture. Cirrhosis also caused increased expression of both receptors. Therefore, agents that stimulate LGR8 and LGR7 may be therapeutically useful to limit the activation of hepatic stellate cells in liver injury.
\end{abstract}

Published by Elsevier Inc.

\section{Introduction}

Relaxin is a member of the insulin superfamily of polypeptide hormones [1]. The earliest characterized functions for relaxin are in pregnancy, where it inhibits uterine contraction, induces softening of the birth canal, and induces lengthening of the interpubic ligament, largely by inducing extracellular matrix remodeling $[1,2]$. Several studies have suggested that relaxin may be effective in the treatment of conditions characterized by excess collagen deposition, including pulmonary, renal, and dermal fibrosis [3-5]. Furthermore, relaxinnull mice were found to develop age-related fibrosis in the

\footnotetext{
* Corresponding author at: Research Service (151), Veterans Affairs Medical Center, 4101 Woolworth Avenue, Omaha, NE 68105, USA. Tel.: +1 402346 8800x3105; fax: +1 4024490604 .

E-mail address: rgbennet@unmc.edu (R.G. Bennett).

Abbreviations: HSC, hepatic stellate cells; SMA, smooth muscle $\alpha$-actin; InsL, insulin-like peptide; LGR, leucine-rich G-protein-coupled receptor 0006-2952/\$ - see front matter. Published by Elsevier Inc. doi:10.1016/j.bcp.2006.12.007
} 
lung, kidney, heart, and skin [6-9]. Together, these findings suggest that relaxin may function as a protective agent against fibrosis outside the reproductive system.

Hepatic fibrosis is characterized by excess deposition of fibrillar collagen and other extracellular matrix components in the liver [10]. Central to this process is the activation of hepatic stellate cells (HSC) from a quiescent, retinoid-storing state to a myofibroblastic phenotype characterized by increased production of collagen and other extracellular matrix components, elevated proliferative rate, expression of $\alpha$-smooth muscle actin (SMA), and increased responsiveness to cytokines $[11,12]$. Normally, HSC activation is an early event in the healing process after liver injury, and upon removal of the injurious stimulus there is a reduction of activated HSC, either through apoptosis or through a return to the quiescent state. Persistent injury results in sustained HSC activation, prolonged extracellular matrix deposition, fibrosis, and ultimately cirrhosis. Therefore, the reduction or reversal of HSC activation is an attractive therapeutic target in the treatment of hepatic fibrosis $[10,13]$.

Relaxin also has effects in the liver. Relaxin treatment of rats caused acute changes in hepatic microcirculation, and induced morphological changes in sinusoidal myofibroblastic cells [14]. In addition, the relaxin-null mouse developed significantly increased liver weight [15], although it was not reported if this phenomenon was due to increased collagen. Relaxin has effects on liver cells, particularly HSC. Relaxin treatment decreased collagen synthesis, total collagen content and SMA protein level in HSC cultures [16,17]. Relaxin also decreased the expression of tissue inhibitors of metalloproteinases (TIMPs) and increased the expression of the rodent interstitial collagenase MMP-13 [16,17]. Finally, relaxin treatment of experimentally induced hepatic fibrosis resulted in decreased liver collagen [17], suggesting that relaxin treatment may benefit hepatic fibrosis in vivo.

Although many physiological functions of relaxin are being identified, the relaxin receptors have only recently been characterized at the molecular level. Two receptors, the leucine-rich G-protein-coupled receptors LGR7 and LGR8 are activated by relaxin [18]. Both are $\mathrm{G}_{\mathrm{s}}$-coupled receptors, and therefore induce cAMP production through activation of adenylyl cyclase [18]. While both receptors are activated by relaxin, there is specificity in their response to other relaxin family members. InsL3 (insulin-like peptide 3, also known as relaxin-like factor and Leydig cell insulin-like peptide) potently activates LGR8, but does not activate LGR7. A third hormone, relaxin-3 (also known as insulin-like peptide 7) can activate LGR7, but displays little activation of LGR8. Using these tools, the present study sought to determine the expression of the relaxin receptors in HSC and in diseased liver tissue.

\section{Materials and methods}

Purified porcine relaxin was generously provided by Dr. O. David Sherwood (University of Illinois at Urbana-Champaign), or was purchased from the National Hormone \& Peptide Program (NIDDK). Human InsL3 and relaxin-3, and antibodies to LGR7 and LGR8 were purchased from Phoenix Pharmaceu- ticals (Belmont, CA). Nycodenz was purchased from Accurate Chemical (Westbury, NY). Peroxidase-conjugated secondary antibodies were from Jackson Immunochemicals (West Grove, PA). The antibodies directed against SMA and desmin were from Sigma (St. Louis, CA).

\subsection{Cell preparation and culture}

Rat HSC were isolated from SAS-Sprague-Dawley rats (400$500 \mathrm{~g}$ ) using sequential perfusion with pronase and collagenase, followed by density gradient centrifugation in Nycodenz as described previously [19]. Cell viability was monitored by trypan blue exclusion, and HSC identified by their typical morphology and the presence of fat droplets under UV illumination. The HSC were maintained in DMEM/Ham's F12 medium supplemented with $10 \%$ fetal bovine serum, $2 \mathrm{mM}$ glutamine, $100 \mathrm{U} / \mathrm{ml}$ penicillin and $100 \mu \mathrm{g} / \mathrm{ml}$ streptomycin at $37{ }^{\circ} \mathrm{C}$ in a humidified $5 \% \mathrm{CO}_{2}$ atmosphere. The medium was changed $24 \mathrm{~h}$ after seeding and every $48 \mathrm{~h}$ thereafter. Within 7-10 days of culture, the HSC displayed the activated (myofibroblastic) phenotype identified by the loss of lipid droplets and the expression of SMA by immunoblotting or immunocytochemistry. At 2 days (quiescent HSC) or 12 days (activated HSC) of growth, the cells were used for experiments.

\section{2. cAMP determination}

HSC cultured for 2 days (quiescent) or 12 days (activated) were seeded into 96-well plates $\left(30,000\right.$ cells $\left./ \mathrm{cm}^{2}\right)$, and grown for $24 \mathrm{~h}$. Cells were serum-deprived $16 \mathrm{~h}$ in DMEM/Ham's F12 medium with $0.1 \% \mathrm{BSA}$, then treated for $30 \mathrm{~min}$ with $0.5 \mathrm{mM}$ isobutylmethyl xanthine (IBMX) to inhibit phosphodiesterase activity. Relaxin (0.01-100 nM), InsL3 or relaxin-3 (1 nM) was then added and cells were incubated for $30 \mathrm{~min}$. Control cells received IBMX treatment as above, then received medium alone. Cells were lysed and intracellular cAMP concentrations determined using the Biotrak EIA kit (Amersham, Piscataway, $\mathrm{NJ}$ ) according to the manufacturer's instructions. Data were normalized to the protein level in the lysates as determined by the bicinchoninic acid (BCA) assay (Pierce, Rockford, IL).

\subsection{Real-time quantitative RT-PCR analysis of receptor expression}

Total RNA was extracted from whole rat liver or cultured HSC using the PureLink system (Invitrogen, Carlsbad, CA). Reverse transcription and quantitative PCR were performed using TaqMan One-Step RT-PCR Master Mix (Applied Biosystems, Foster City, CA). The TaqMan intron-spanning primers and TAMRA-labeled probes sets used were Rn01495351_m1 (LGR7), Rn01412901_m1 (LGR8), and Hs99999901_s1 (18S rRNA). The expression level of LGR7 and LGR8 were determined relative to that of ribosomal 18S RNA using the comparative $\mathrm{C}_{\mathrm{T}}$ method. The data are presented as the expression level relative to that of LGR7 in control liver or quiescent HSC.

\subsection{Immunocytochemistry}

HSC were grown on 8-well glass chamber slides for 12 days before use. Cells were fixed with $4 \%$ paraformaldehyde for 
10 min, washed in PBS (50 mM sodium phosphate, $\mathrm{pH} 7.4$, $0.15 \mathrm{M} \mathrm{NaCl}$ ) then permeabilized in $0.1 \%$ Triton X-100 in PBS for $10 \mathrm{~min}$. Endogenous peroxidase activity was quenched by incubation in $3 \% \mathrm{H}_{2} \mathrm{O}_{2}$ in $\mathrm{PBS}$ for $5 \mathrm{~min}$, and non-specific binding was minimized by incubation in blocking buffer $(3 \%$ BSA, 0.1\% Tween-20 in PBS) for 30 min. Cells were then probed with monoclonal antibodies to SMA or desmin (1:400), or polyclonal antibodies to LGR7 and LGR8 (1:200) in blocking buffer for $1 \mathrm{~h}$. Control cells were probed with appropriately diluted non-immune mouse IgG or rabbit serum. Immunoreactive proteins were detected using the $A B C$ system (Vector Labs, Burlingame, CA), and visualized with DAB staining. Cells were counterstained with hematoxylin, dehydrated, and mounted.

\subsection{Experimental liver disease}

All procedures involving animals conformed to The Guide for the Care and Use of Laboratory Animals, and were approved by the Omaha VA Subcommittee of Animals Studies (IACUC). Cirrhosis was induced in male Sprague-Dawley rats as described previously [20]. Briefly, rats were fed standard chow ad libitum and given water containing $1.5 \mathrm{mM}$ phenobarbital for 12 weeks. When the rats reached approximately $200 \mathrm{~g}, \mathrm{CCl}_{4}$ was administered weekly by intragastric gavage, with an initial dose of $0.04 \mathrm{ml}$. Each subsequent dose of $\mathrm{CCl}_{4}$ was adjusted in increments of $0.04 \mathrm{ml}$ based on the percentage of body weight gained or lost within 2 days of the previous week's $\mathrm{CCl}_{4}$ treatment, according to the system devised by Proctor and Chatamra [21]. Control rats received water containing phenobarbital for the same period of time. At the end of treatment, samples of the livers were removed, fixed in formalin, and embedded in paraffin.

\subsection{Immunohistochemistry}

Sections of fixed, paraffin-embedded tissue from human specimens of cirrhotic or non-cirrhotic liver tissue, or rat liver as described above, were dewaxed, then subject to antigen retrieval using Antigen Unmasking Solution (Vector Labs, Burlingame, CA) and autoclaving for $15 \mathrm{~min}$. After a $5 \mathrm{~min} 3 \% \mathrm{H}_{2} \mathrm{O}_{2}$ for $5 \mathrm{~min}$ to quench endogenous peroxidases, sections were blocked for 30 min blocking buffer. Sections were probed with rabbit polyclonal antibodies to LGR7 and LGR8 (1:200), or mouse monoclonal antibody to SMA (1:400), diluted in blocking buffer. To assess background reactivity, control slides were probed with appropriately diluted nonimmune rabbit serum or mouse IgG. Immunoreactive proteins were detected using a biotin-fee system (EnVision, Dako, Carpinteria, CA), and DAB staining. After counterstaining with haematoxylin, the slides were dehydrated and mounted.

\subsection{Statistics}

All data are expressed as mean \pm S.E. Comparisons for differences between groups were made by ANOVA with Tukey's post-test. $p<0.05$ was interpreted as significant. Curve-fitting was performed using the Prism 4.0 software package (GraphPad Inc., San Diego, CA).

\section{Results}

Previous studies showed that HSC respond to relaxin treatment $[16,17]$. The two receptors activated by relaxin are LGR7 and LGR8, which are $\mathrm{G}_{\mathrm{s}}$-coupled receptors that induce cAMP production when activated by relaxin [18]. To determine if HSC possess functioning relaxin receptors, activated cells were treated with relaxin, and cAMP production was measured after 30 min. Relaxin treatment induced a dose-dependent elevation in CAMP (Fig. 1). The maximal increase was approximately three-fold, at $1 \mathrm{nM}$ relaxin. To determine which receptors were present, selective agonists of relaxin receptors were used. Insulin-like peptide 3 (InsL3), also known as relaxin-like factor, is a selective activator of LGR8 [22]. Another relaxin family member, relaxin-3 (also known as InsL7), is a selective activator of LGR7 [23]. Treatment of activated HSC with either relaxin-3 or InsL3 significantly increased cellular CAMP to a level comparable to that induced by relaxin (Fig. 2). In contrast, treatment of quiescent cells resulted in no response to relaxin or InsL3, and a small but statistically insignificant increase in cAMP with relaxin-3 treatment. These data suggest that activated HSC are sensitive to relaxin receptor agonists, but that quiescent HSC have a reduced or absent response.

To determine examine relaxin receptor expression in HSC during the progression to the activated phenotype, isolated cells were cultured for 2 days (quiescent HSC) through 12 days (activated HSC). The levels of the transcripts for LGR7 and LGR8 were determined using quantitative real-time RT-PCR using specific primer and probe sets. All values were normalized to the level of $18 \mathrm{~S}$ ribosomal RNA. In quiescent cells (cultured for 2 days), a relatively low level of expression of LGR7 was detected (Fig. 3). At day 4 the expression had increased four-fold, and this level was maintained through day 8. By days 10-12, a dramatic increase in LGR7 expression to more than 30 -fold of the day 2 level was detected. In contrast,

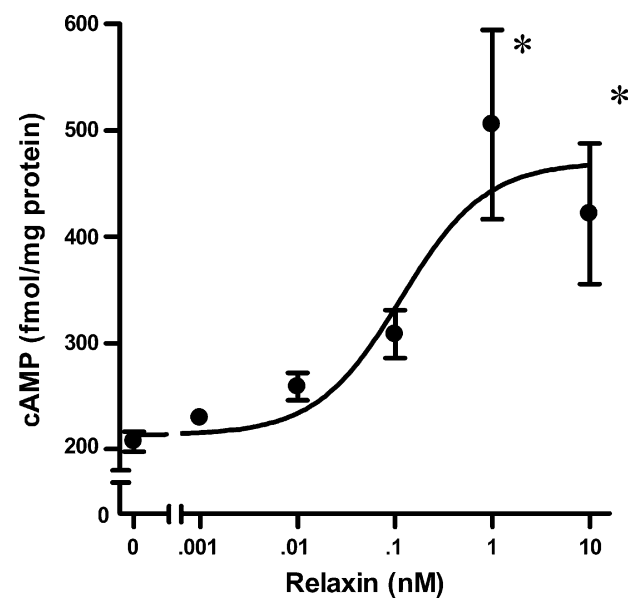

Fig. 1 - Elevation of cAMP levels by relaxin. Activated HSC were serum-deprived overnight, then treated with $0.5 \mathrm{mM}$ IBMX for $\mathbf{3 0} \mathrm{min}$. Cells were treated with relaxin at the indicated concentrations for $30 \mathrm{~min}$. The concentration of cAMP was determined using an EIA kit (Amersham). Data are expressed as fmoles cAMP per $\mathrm{mg}$ total protein, mean \pm S.E.M. for five determinations. ${ }^{*} p<0.001$ compared with untreated cells. 


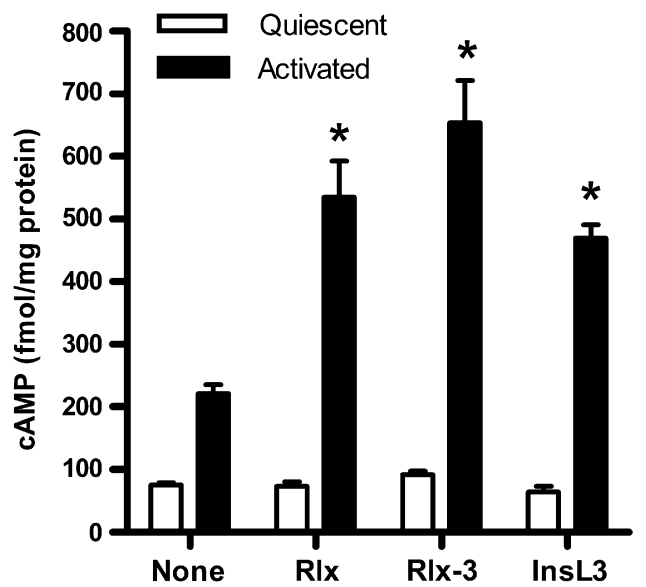

Fig. 2 - Relaxin family peptides induce cAMP production in HSC. Quiescent or activated HSC were serum-deprived overnight, then treated with $0.5 \mathrm{mM}$ IBMX for $30 \mathrm{~min}$. Cells were then treated with $1 \mathrm{nM}$ relaxin, InsL3 or relaxin-3 for $30 \mathrm{~min}$. The concentration of cAMP was determined using an EIA kit (Amersham). Data are expressed as fmoles cAMP per $\mathrm{mg}$ total protein, mean \pm S.E.M. for three determinations. ${ }^{*} p<0.05$ compared to untreated cells.

LGR8 expression was undetectable until day 8. From days 1012, a marked increase in LGR8 expression occurred, reaching a level 60-fold higher than the initial level of LGR7. These findings suggest that quiescent HSC express LGR7 at low levels, but that transdifferentiation of HSC to the myofibroblastic phenotype is accompanied by a marked increase in LGR7 and LGR8 expression.

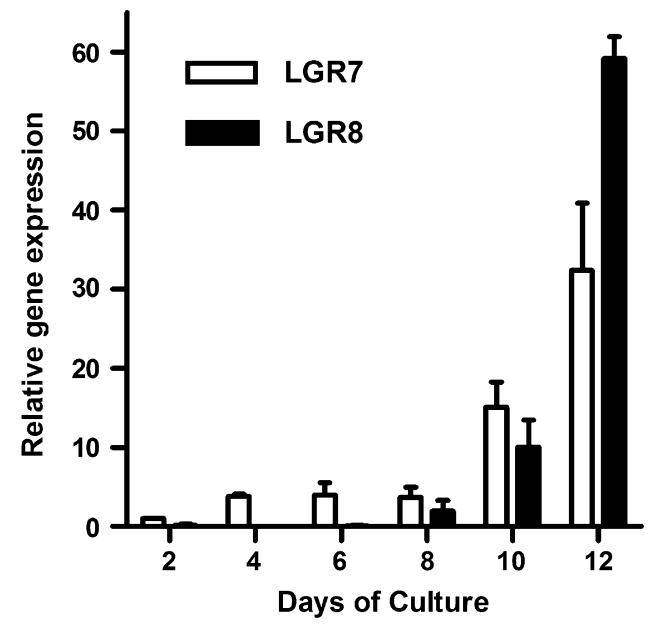

Fig. 3 - Relaxin receptor expression in HSC. Expression of LGR7 or LGR8 was determined by real-time TaqMan RTPCR analysis of RNA from primary rat HSC. Cells were cultured for 2 days (quiescent) or up to 12 days (activated). Total RNA was analyzed by TaqMan using validated primer/probe sets for LGR7, LGR8, or 18S ribosomal RNA as an internal standard. Expression levels are relative to that of LGR7 transcript at 2 days. Data are from three independent experiments.

To examine the expression of LGR7 and LGR8 proteins in HSC, activated cells were fixed and examined by immunocytochemistry for the presence of LGR7, LGR8, SMA, or desmin (Fig. 4). The cells showed positive staining for LGR7 and LGR8 compared to non-immune rabbit serum. As expected, SMA was readily detectable, while desmin expression was absent in
LGR7

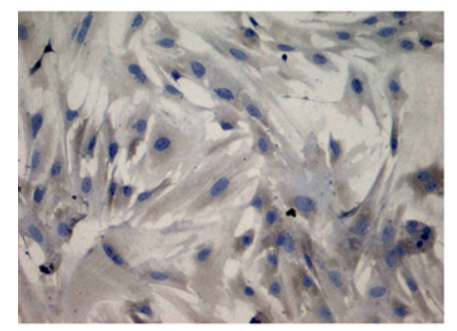

SMA

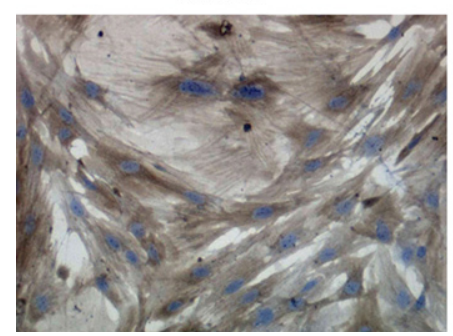

LGRb

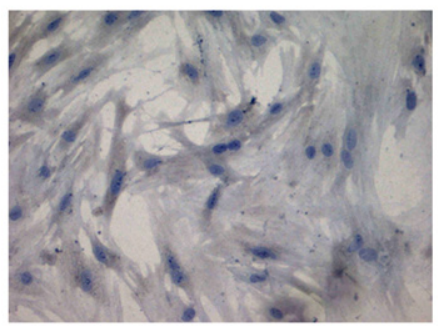

Desmin

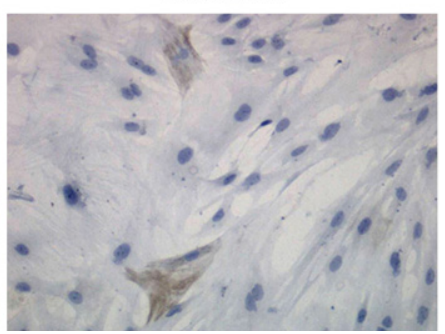

Rb serum

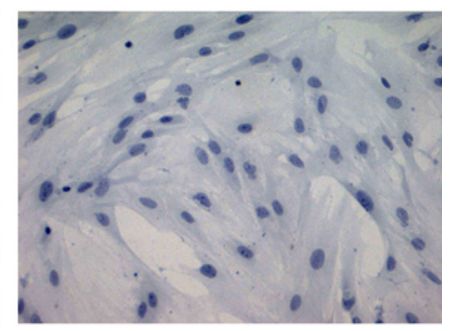

Ms IgG

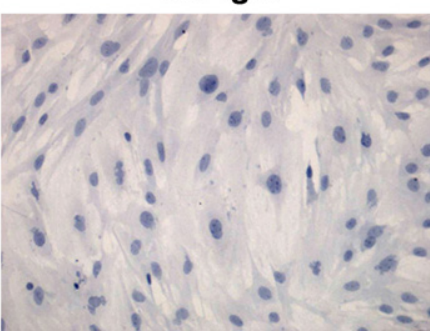

Fig. 4 - Immunocytochemical detection of LGRs in activated HSC. Primary HSC were cultured for 12 days, then were analyzed by immunocytochemistry using rabbit polyclonal antibodies directed against LGR7 or LGR8, or mouse monoclonal antibodies directed against SMA or desmin. Control cells were probed with non-immune rabbit serum or mouse IgG at the same dilution. Immunoreactive proteins were detected with peroxidase-conjugated secondary antibodies and DAB.

Original magnification: $100 \times$. 
the majority of cells, verifying the activated HSC phenotype [24]. Non-immune mouse IgG produced no positive signal. These data confirm at the protein level the gene expression data demonstrating that LGR7 and LGR8 are expressed by activated HSC.

Hepatic fibrosis is characterized by the transdifferentiation of HSC to the activated, myofibroblastic phenotype. To determine if relaxin receptor expression is increased in activated HSC in vivo, a rodent model of cirrhosis was used. Rats were treated for 12 weeks with $\mathrm{CCl}_{4}$ to induce cirrhosis, the total liver RNA was extracted and analyzed for LGR7 and LGR8 expression by quantitative real-time RT-PCR (Fig. 5). In control liver, a low level of LGR7 expression was detected. In three of four control liver specimens, LGR8 expression was completely undetectable. In contrast, cirrhotic livers had significantly elevated levels of both LGR7 and LGR8 transcripts. These data mirror the results using isolated HSC suggesting an induction of relaxin receptor expression with HSC activation.

To confirm the gene expression results at the protein level, fixed paraffin-embedded sections of control and cirrhotic rat liver were analyzed by immunohistochemistry for presence of for LGR7, LGR8, or SMA (Fig. 6). No immunoreactivity against LGR7 or LGR8 was detectable in normal tissue. In cirrhotic tissue, LGR7 and LGR8 immunoreactivity was readily detectable, predominantly at the outer edge of the fibrotic septae adjacent to hepatocytes. For comparison, SMA immunoreactivity was limited to vascular smooth muscle cells in control liver, but present in perivenular areas and in and around the fibrotic septae in cirrhotic tissue. Taken together, these data support the gene expression data showing increased LGR7 and LGR8 expression in diseased liver. The localization of relaxin receptors in diseased liver was similar, but not identical, to the pattern seen for SMA. Finally, similar results were obtained using human liver (Fig. 7). In cirrhotic tissue, both LGR7 and LGR8 immunoreactivity was detected in and around the fibrotic scar. No LGR8 immunoreactivity was detectable in

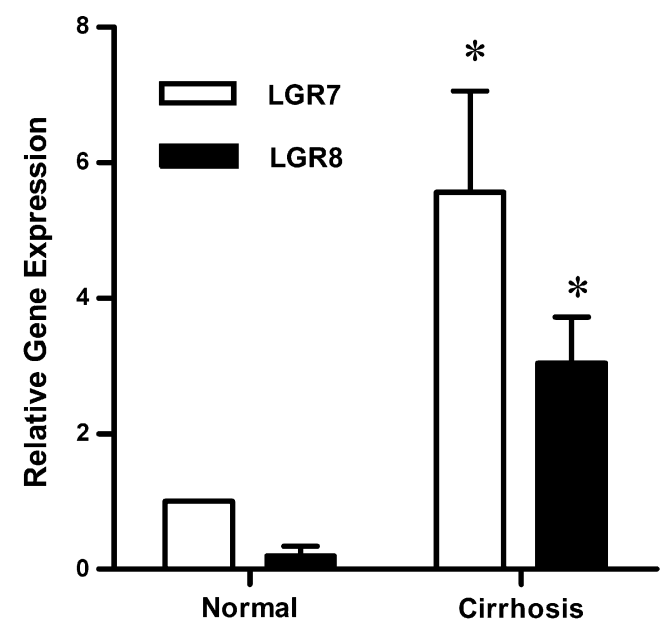

Fig. 5 - Relaxin receptor expression in normal or cirrhotic rat tissue. Rats were treated or not for 12 weeks with carbon tetrachloride to induce cirrhosis. Total RNA extracted from liver was probed for LGR7 or LGR8 by TaqMan real-time RT-PCR using 18S RNA as an internal control. All data shown are relative to the level of LGR7 in normal liver. ${ }^{*} p<0.05$ compared to normal, $n=4$. non-cirrhotic tissue. However, some perisinusoidal cells did show positive immunoreactivity toward LGR7 in non-cirrhotic tissue (inset).

\section{Discussion}

Previous studies had demonstrated antifibrotic effects of relaxin on HSC. In addition to a decrease in total collagen levels, the rate of new collagen synthesis was reduced, and the level of type I collagen was decreased $[16,17]$. The level of the matrix metalloproteinase MMP13 was increased, while the levels of the tissue inhibitors of metalloproteinases TIMP1 and TIMP2 were decreased, suggesting that relaxin induces a matrix degrading phenotype in activated HSC $[16,17]$. In addition, the level of SMA was reduced with relaxin exposure, raising the possibility that relaxin may have effects on portal hypertension [16]. Finally, relaxin treatment of experimental hepatic fibrosis resulted in a decrease in liver collagen content [17]. While these studies inferred the presence of receptors in the liver, the lack of identification of a distinct cognate receptor hampered the study of relaxin receptors in the liver. The identification of the relaxin receptors LGR7 and LGR8 [18] now allows those studies to be performed.

Treatment with relaxin-3 or InsL3, selective activators of LGR7 and LGR8, respectively, induced cAMP production to the same level as relaxin, which activates both receptors. This is possibly due to the fact that relaxin has approximately threefold lower affinity for LGR8 than LGR7 [18]. However, some caution should be used with interpretation of these data. As discussed earlier, porcine relaxin activates both LGR7 and LGR8 from human, rat or mouse sources. But recent evidence suggests that mouse or rat relaxin activates only LGR7 in these species [25]. This was further illustrated by the inability of mouse relaxin to rescue the failed testicular descent in the InsL3-null mouse [26], and thus in the rodent, InsL3 alone is responsible for activation of LGR8. One study has suggested that human relaxin-3 may activate rat LGR8 [25], and therefore it is possible that the increased cAMP in HSC exposed to porcine relaxin, or human InsL3 and relaxin-3, may be due to activation of LGR8.

Two additional receptors for relaxin-3 have been identified, known as GPCR135 (RXFP3) and GPCR142 (RXFP4) [27,28]. Neither of these receptors is activated by relaxin or InsL3. GPCR142 is a pseudogene in rats, and therefore is uninvolved in our studies. Furthermore, both GPCR135 and GPCR142 are coupled to $G_{i}$, and therefore decrease cAMP production. Therefore, our data suggest that, in HSC, LGR7 and LGR8 are the receptors responsible for the increase in CAMP in response to relaxin receptor agonists.

The expression of both relaxin receptors was detectable in culture activated HSC, at both the mRNA and protein levels. The presence of the receptors provides a means for the relaxin effects previously seen in HSC. Relaxin induced an increase in the cAMP levels in these cells, consistent with activation of a $\mathrm{G}_{\mathrm{s}}$-coupled receptor pathway. Interestingly, increased cAMP has been implicated in the inhibition of markers of HSC activation. Treatment of HSC with stable analogues of cAMP, or agents that inhibit phosphodiesterases, resulted in retention of retinoid stores, suppressed SMA expression, decreased 


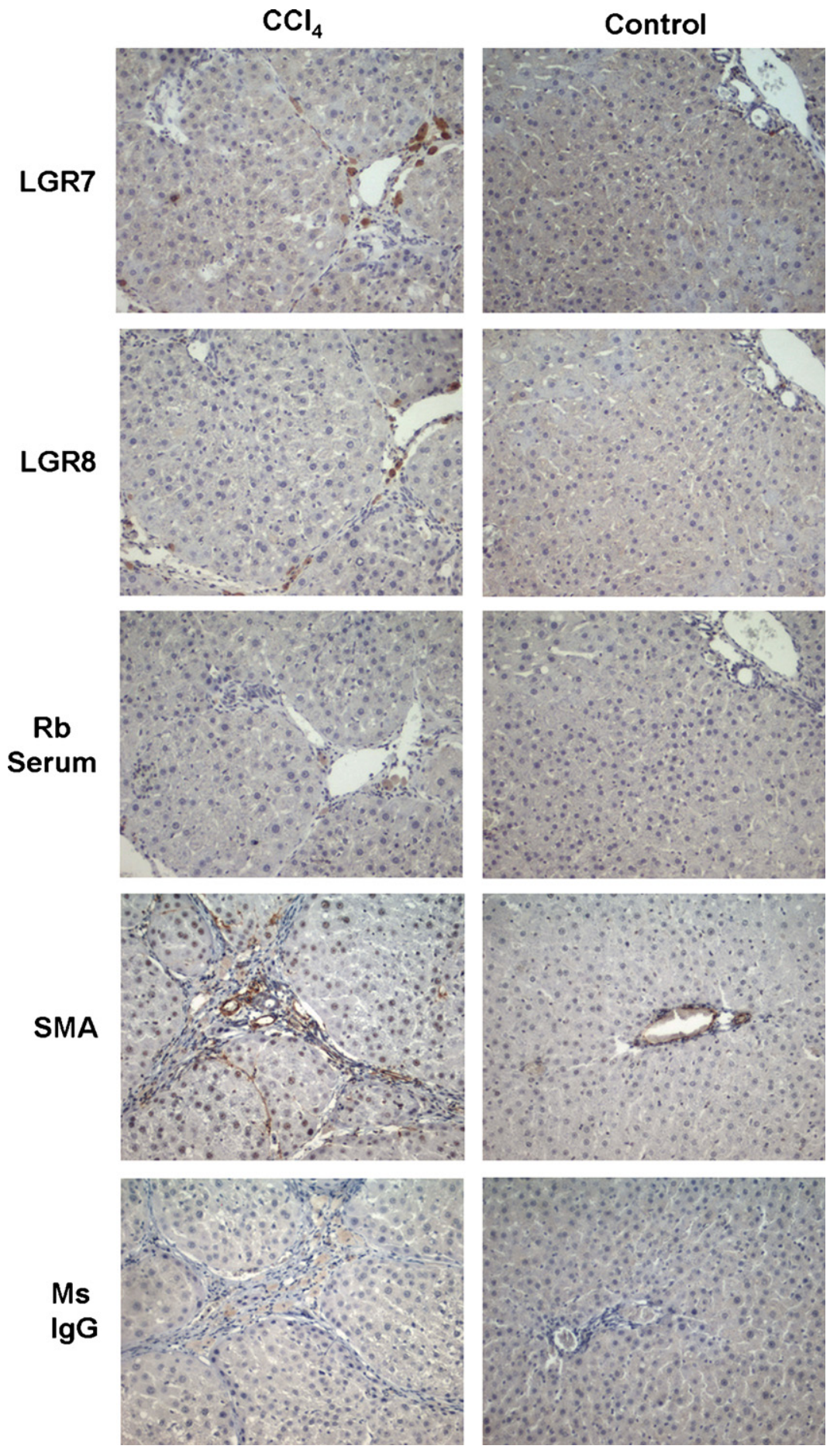

Fig. 6 - Immunohistochemical detection of relaxin receptors in cirrhotic rat liver. Rats were treated with carbon tetrachloride for 12 weeks to induce cirrhosis, and then probed with rabbit polyclonal antibodies to LGR7 or LGR8, or a mouse monoclonal antibody to SMA, as described in Section 2. Control sections were probed with non-immune rabbit serum or mouse IgG at the same protein level. Immunoreactive proteins were detected by peroxidase-conjugated secondary antibodies and DAB staining. Original magnification: $100 \times$.

proliferation, reduced collagen expression, and blunted sensitivity to endothelin-1 [29-33]. Therefore, cAMP elevation may be the mechanism of action for relaxin in these cells.

Previous studies examining hepatic expression of LGRs have been inconsistent. Using total RNA from liver, transcripts for LGR7 and LGR8 were either undetectable [34], or LGR7 only was detected $[35,36]$. However, it should be noted that in both of these cases, normal (non-diseased) liver was the source of the analyzed samples. The results of the present study suggest that only LGR7 is expressed in normal tissue, but expression of 


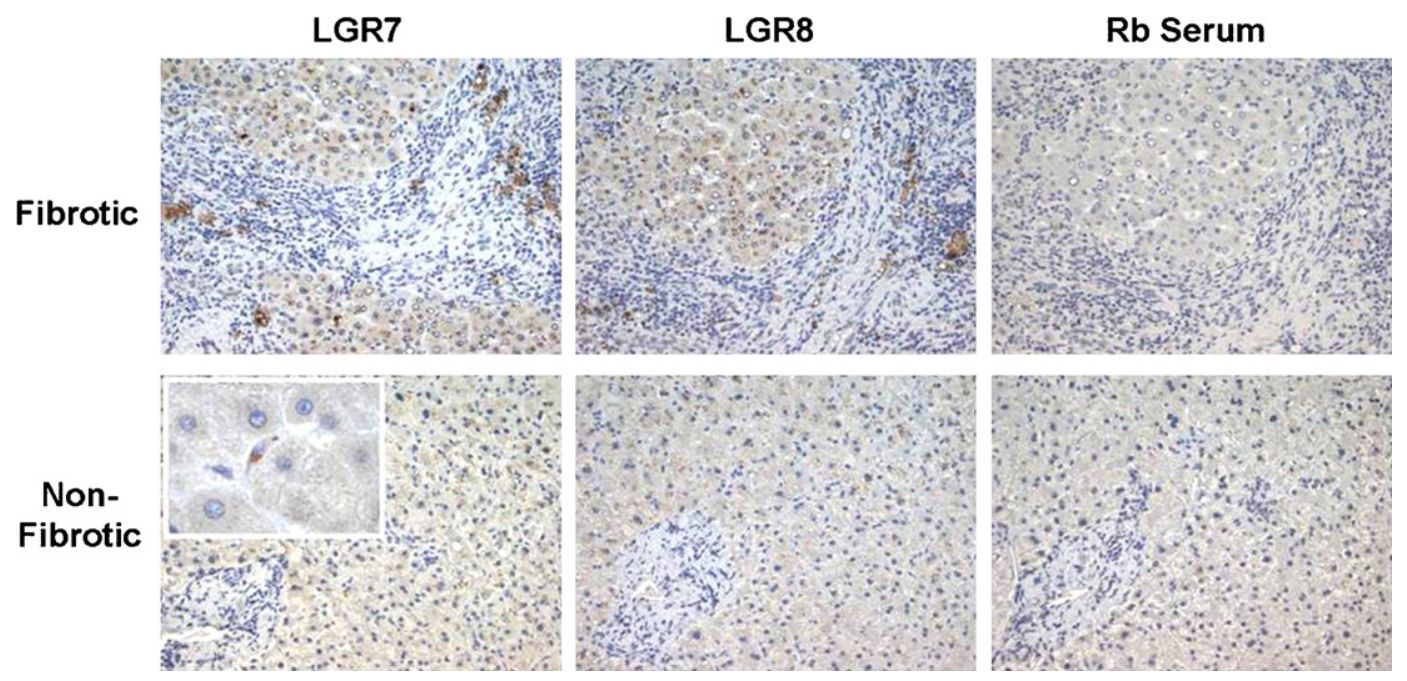

Fig. 7 - Relaxin receptor immunoreactivity human cirrhosis. Sections of cirrhotic or non-cirrhotic human liver were probed with antibodies to LGR7 or LGR8, or non-immune rabbit serum protein level. Immunoreactive proteins were detected by peroxidase-conjugated secondary antibodies and DAB staining. Original magnification: $100 \times$ or $400 \times$ (inset).

both LGR8 and LGR7 is upregulated with HSC activation. The presence of relaxin receptors was detected in liver tissue from diseased animals, but not in control animals. Despite the findings of LGR7 transcript and protein in quiescent HSC, no LGR7 immunoreactivity was detectable in control (noncirrhotic) liver in the rat. However, LGR7 immunoreactivity was detected in perisinusoidal cells in non-cirrhotic human tissue, consistent with quiescent HSC, but this finding was relatively rare. This may be due to the low level of LGR7 expression in quiescent cells that was revealed in the gene expression studies. Alternatively, it is possible that the extraction of HSC and culture for 2 days produces the induction of LGR7 expression in culture that is not reflected in quiescent HSC in vivo.

The receptors were localized to the same areas that were SMA positive, suggesting that they may be expressed in HSC. However, the pattern of expression was not identical to SMA, and may reflect a subset of HSC. Therefore, it may be that, in vivo, the receptors are expressed only after the HSC have become activated and have begun to participate in the healing process. The relaxin receptors may then be involved in inhibiting the sustained activation of HSC during the resolution process where matrix production slows and excess matrix deposition is cleared. Further studies are needed to examine the temporal expression of LGR7 and LGR8 during disease progression and resolution.

Few studies have been performed examining the effects of relaxin treatment on the liver in vivo. As discussed earlier, relaxin treatment reduced the effects of carbon tetrachlorideinduced fibrosis [17]. Interestingly, effects of relaxin have been detected in normal (undiseased) liver. Porcine relaxin treatment caused morphological changes in rat perisinusoidal liver cells, and dilation of the sinusoids [14]. Relaxin had protective effects against ischemia and reperfusion damage in perfused rat liver [37]. In a recent study, 20-fold overexpression of mouse relaxin for 4 months in a transgenic mouse model resulted in increased liver weight and hydroxyproline in males but not females [26]. Because mouse relaxin does not activate LGR8, and because our data suggests that only a low level of LGR7 is expressed in non-fibrotic liver, these effects would presumably be mediated by LGR7 alone. In addition, because the phenomenon was observed in males only, additional gender-specific factors are involved in the relaxin response. Clearly, further studies are needed to identify the roles that LGR7 and LGR8 each play in the regulation of collagen production in the liver.

In summary, this is the first report of relaxin receptor expression in liver cells. These findings were supported by the detection of relaxin family peptide receptor expression in diseased liver tissue. These studies expand the earlier studies reporting effects of relaxin on HSC and experimental liver disease, and raise the possibility that InsL3 or relaxin-3 may be additional agents useful in the treatment of chronic liver injury.

\section{Acknowledgements}

This work was supported by funding from the VA Merit Review Program (R.G.B., M.J.G., D.J.T.) and the Bly Memorial Research Fund (R.G.B.). We thank Dr. Richard Tobin for his support of this project.

\section{RE F E R E N C E S}

[1] Sherwood OD. Relaxin's physiological roles and other diverse actions. Endocr Rev 2004;25:205-34.

[2] Bryant-Greenwood GD, Schwabe C. Human relaxins: chemistry and biology. Endocr Rev 1994;15:5-26.

[3] Garber SL, Mirochnik Y, Brecklin CS, Unemori EN, Singh AK, Slobodskoy L, et al. Relaxin decreases renal interstitial fibrosis and slows progression of renal disease. Kidney Int 2001;59:876-82. 
[4] Unemori EN, Bauer EA, Amento EP. Relaxin alone and in conjunction with interferon-gamma decreases collagen synthesis by cultured human scleroderma fibroblasts. J Invest Dermatol 1992;99:337-42.

[5] Unemori EN, Pickford LB, Salles AL, Piercy CE, Grove BH, Erikson ME, et al. Relaxin induces an extracellular matrixdegrading phenotype in human lung fibroblasts in vitro and inhibits lung fibrosis in a murine model in vivo. J Clin Invest 1996;98:2739-45.

[6] Samuel CS, Unemori EN, Mookerjee I, Bathgate RA, Layfield SL, Mak J, et al. Relaxin modulates cardiac fibroblast proliferation, differentiation, and collagen production and reverses cardiac fibrosis in vivo. Endocrinology 2004;145:4125-33.

[7] Samuel CS, Zhao C, Bathgate RA, Bond CP, Burton MD, Parry $\mathrm{LJ}$, et al. Relaxin deficiency in mice is associated with an age-related progression of pulmonary fibrosis. FASEB J 2003;17:121-3.

[8] Samuel CS, Zhao C, Bond CP, Hewitson TD, Amento EP, Summers RJ. Relaxin-1-deficient mice develop an agerelated progression of renal fibrosis. Kidney Int 2004;65:2054-64.

[9] Samuel CS, Zhao C, Yang Q, Wang H, Tian H, Tregear GW, et al. The relaxin gene knockout mouse: a model of progressive scleroderma. J Invest Dermatol 2005;125:692-9.

[10] Friedman SL. Liver fibrosis-from bench to bedside. J Hepatol 2003;38(Suppl. 1):S38-53.

[11] Tsukada S, Parsons CJ, Rippe RA. Mechanisms of liver fibrosis. Clin Chim Acta 2006;364:33-60.

[12] Friedman SL. Stellate cells: a moving target in hepatic fibrogenesis. Hepatology 2004;40:1041-3.

[13] Murphy F, Arthur M, Iredale J. Developing strategies for liver fibrosis treatment. Expert Opin Invest Drugs 2002;11:1575-85.

[14] Bani D, Nistri S, Quattrone S, Bigazzi M, Bani Sacchi T. The vasorelaxant hormone relaxin induces changes in liver sinusoid microcirculation: a morphologic study in the rat. J Endocrinol 2001;171:541-9.

[15] Du X-J, Samuel CS, Gao X-M, Zhao L, Parry LJ, Tregear GW. Increased myocardial collagen and ventricular diastolic dysfunction in relaxin deficient mice: a gender-specific phenotype. Cardiovasc Res 2003;57:395-404.

[16] Bennett RG, Kharbanda KK, Tuma DJ. Inhibition of markers of hepatic stellate cell activation by the hormone relaxin. Biochem Pharmacol 2003;66:867-74.

[17] Williams EJ, Benyon RC, Trim N, Grove BH, Arthur MJ, Unemori EN, et al. Relaxin inhibits effective collagen deposition by cultured hepatic stellate cells and decreases rat liver fibrosis in vivo. Gut 2001;49:577-83.

[18] Hsu SY, Nakabayashi K, Nishi S, Kumagai J, Kudo M, Sherwood OD, et al. Activation of orphan receptors by the hormone relaxin. Science 2002;295:671-4.

[19] Hendriks HF, Verhoofstad WA, Brouwer A, de Leeuw AM, Knook DL. Perisinusoidal fat-storing cells are the main Vitamin A storage sites in rat liver. Exp Cell Res 1985;160:138-49.

[20] Gentry-Nielsen MJ, Preheim LC, Lyman KN, McDonough $\mathrm{KH}$, Potter BJ. Use of rat models to mimic alterations in iron homeostasis during human alcohol abuse and cirrhosis. Alcohol 2001;23:71-81.

[21] Proctor E, Chatamra K. High yield micronodular cirrhosis in the rat. Gastroenterology 1982;83:1183-90.
[22] Kumagai J, Hsu SY, Matsumi H, Roh JS, Fu P, Wade JD, et al. InsL3/Leydig insulin-like peptide activates the LGR8 receptor important in testis descent. J Biol Chem 2002;277:31283-6.

[23] Sudo S, Kumagai J, Nishi S, Layfield S, Ferraro T, Bathgate RA, et al. H3 relaxin is a specific ligand for LGR7 and activates the receptor by interacting with both the ectodomain and the exoloop 2. J Biol Chem 2003;278:7855-62.

[24] Knittel T, Kobold D, Saile B, Grundmann A, Neubauer K, Piscaglia F, et al. Rat liver myofibroblasts and hepatic stellate cells: different cell populations of the fibroblast lineage with fibrogenic potential. Gastroenterology 1999;117:1205-21.

[25] Scott DJ, Fu P, Shen PJ, Gundlach AL, Layfield S, Riesewijk A, et al. Characterization of the rat InsL3 receptor. Ann NY Acad Sci 2005;1041:13-6.

[26] Feng S, Bogatcheva NV, Kamat AA, Truong A, Agoulnik AI. Endocrine effects of relaxin overexpression in mice. Endocrinology 2006;147:407-14.

[27] Liu C, Chen J, Sutton S, Roland B, Kuei C, Farmer N, et al. Identification of Relaxin-3/INSL7 as a ligand for GPCR142. J Biol Chem 2003;278:50765-70.

[28] Liu C, Eriste E, Sutton S, Chen J, Roland B, Kuei C, et al. Identification of Relaxin-3/INSL7 as an endogenous ligand for the orphan G-protein-coupled receptor GPCR135. J Biol Chem 2003;278:50754-6.

[29] Houglum K, Lee KS, Chojkier M. Proliferation of hepatic stellate cells is inhibited by phosphorylation of CREB on serine 133. J Clin Invest 1997;99:1322-8.

[30] Kawada N, Kuroki T, Kobayashi K, Inoue M, Kaneda K. Inhibition of myofibroblastic transformation of cultured rat hepatic stellate cells by methylxanthines and dibutyryl CAMP. Dig Dis Sci 1996;41:1022-9.

[31] Reinehr R, Fischer R, Haussinger D. Regulation of endothelin-A receptor sensitivity by cyclic adenosine monophosphate in rat hepatic stellate cells. Hepatology 2002;36:861-73.

[32] Shimizu E, Kobayashi Y, Oki Y, Kawasaki T, Yoshimi T, Nakamura H. OPC-13013, a cyclic nucleotide phosphodiesterase type III, inhibitor, inhibits cell proliferation and transdifferentiation of cultured rat hepatic stellate cells. Life Sci 1999;64:2081-8.

[33] Solis-Herruzo JA, Hernandez I, De la Torre P, Garcia I, Sanchez JA, Fernandez I, et al. G proteins are involved in the suppression of collagen alpha 1 (I) gene expression in cultured rat hepatic stellate cells. Cell Signal 1998;10:17383.

[34] Kubota Y, Temelcos C, Bathgate RA, Smith KJ, Scott D, Zhao C, et al. The role of insulin 3, testosterone Mullerian inhibiting substance and relaxin in rat gubernacular growth. Mol Hum Reprod 2002;8:900-5.

[35] Hsu SY, Nakabayashi K, Nishi S, Kumagai J, Kudo M, Bathgate RA, et al. Relaxin signaling in reproductive tissues. Mol Cell Endocrinol 2003;202:165-70.

[36] Scott DJ, Layfield S, Riesewijk A, Morita H, Tregear GW, Bathgate RAD. Characterization of the mouse and rat relaxin receptors. Ann NY Acad Sci 2005;1041:8-12.

[37] Boehnert MU, Hilbig H, Armbruster FP. Relaxin as an additional protective substance in preserving and reperfusion solution for liver transplantation, shown in a model of isolated perfused rat liver. Ann NY Acad Sci 2005;1041:434-40. 